\title{
Television Serials as Career Stepping Stones: An Empirical Analysis of Employment Paths of Professional Actors
}

\author{
Kay H. Hofmann
}

Accepted: 8 October 2021 / Published online: 9 November 2021

(C) The Author(s) 2021

\begin{abstract}
Guided by cultural labor economics, the paper analyzes the career paths of former actors from popular television soap operas, and addresses in particular, if and under which conditions such serial engagements may function as a stepping stone for a subsequent professional acting career. A novel database of 396 German artists with detailed and long-term biographical information is used for the quantitative empirical analyses. The results indicate that soaps, contrary to popular opinion, function as a stepping stone, especially for younger actors. However, soap engagements should be rather short but long enough to allow artists to play multiple roles in other shows or films besides being in the cast of a soap. While formal acting education does not influence soap actors' future filmographies, there is evidence that it helps artists to find jobs in arts-related occupations such as voice acting. Finally, publicity and media presence foster a later acting career. Practical implications for artists and their managers are outlined, along with a discussion on the meaning of serials for the creation and commercialization of stars.
\end{abstract}

Keywords Cultural labor markets · Contingent work · Television series · Soap opera $\cdot$ Acting $\cdot$ Actor career

JEL J24 $\cdot$ L82 $\cdot$ M29 $\cdot$ Z19

Availability of data and material Secondary data gathered by the author.

Kay H. Hofmann $(\bowtie)$

Osnabrück University of Applied Sciences, Caprivistraße 30a, 49076 Osnabrück, Germany

E-Mail: k.hofmann@hs-osnabrueck.de 


\section{Introduction}

Despite a rather deprecative public opinion and critics, who often deny soap operas any cultural value or aesthetic legitimacy (Scardaville 2009), at times dismissing the genre as 'trash', 'dirty gossip' or even 'serialized drool' (Patten 1975), soap operas enjoy great popularity around the world. In fact, large audiences are fascinated by the packaged but never-ending narratives. Easily accessible plots that are similar to the perceived realities and/or desires of the viewers and a daily routine of emotional interactions with the fictional characters (Hayward 2009, p. 144) cause a high degree of audience involvement (Hayward 2009, p. 146; Rubin and Perse 1987). In consequence, soap operas and the characters depicted therein have a significant influence on viewers' opinions and attitudes (Tamborini et al. 2010) as well as on behavior such as consumption (Anitha 2014). From a business point of view, high audience ratings and low production costs explain why broadcasting companies have been airing countless soap operas-some of them running over decades.

Soap operas require comparatively large casts that embody clusters of more or less equally important characters. Their frequent interactions within a tightly knit social network provide the basis for interpersonal conflicts, amorous adventures and other strokes of fate that carry the interwoven storylines. Over time, producers gradually adapt the community of protagonists by eliminating certain characters and introducing new ones, but the absence of a single or a few main actors supports the open-endedness of these series (Allen 1995, p. 18). Large casts are also supportive of developing narratives that appeal to a broad and diverse audience. That includes depicting a multitude of different stereotype characters. Hence, producers must recruit actors that meet the criteria for a credible embodiment, making casting decisions more contingent on physical suitability, especially facially, and fit with the desired stereotype (Reynolds 1998, p. 161) and less contingent on acting skills, talent or intensive training, which may even be a disadvantage (Moore 2004, p. 73). Ultimately, casts consist of a wide mix of artists with different levels of professional expertise.

Acting jobs in these series are commonly perceived as inferior in terms of artistic aspiration, financial attractiveness (Kirsch 2001) and cultural merit. Although the working conditions are known to be demanding (Cantrell and Hogg 2017), a sufficient number of artists accept the industrialized mass production processes, often without their names being mentioned in the front credits. This raises the question, if there are any 'unobvious' benefits of acting in soap operas that justify otherwise inferior conditions.

The existent academic literature on soap operas typically adopts a sociological lens, with studies predominantly addressing cultural, gender and reception issues (Dunleavy 2009; Hayward 2009; Brasch 2006; Reijnders et al. 2006; Brennan 2004; Götz 2000; Greenberg and Woods 1999; O’Donnell 1999; Liebes and Livingstone 1998; Riegel 1996; Allen 1995). Research on economic and business aspects of soaps and related formats is scarce (Opitz and Hofmann, 2008; Franck and Nüesch 2007) and has mainly analyzed product placements and consumer behavior (Dias et al. 2017; Russell and Stern 2006). Despite a broad and well-established literature on cultural labor markets in which artists participate as suppliers of their services (Towse 
2006; Throsby 2006; Menger 2006; Alper and Wassall 2006; Caserta and Cuccia 2001; Benhamou 2000; Throsby 1996), research on individual actors ${ }^{1}$ as central inputs in the production of media content, if existent, focuses on motion picture artists and film stars (Hofmann 2021; McKenna 2019; Hofmann and Opitz 2019; Wirtz et al. 2016a; Wirtz et al. 2016b; Jones and DeFillippi 1996). Recent exceptions with an emphasis on TV and serial acting include Perez et al. (2020), Rawlins (2020), Hogg and Smith (2020), Middleton and Middleton (2017), Cantrell and Hogg (2017), Vicentini and Boccardelli (2016) and Harrington and Brothers (2010). Most of these studies, however, stem from the field of sociology. The paper at hand complements this research stream by exploring economic and managerial aspects of acting in daily soaps. In particular, we address if and under which conditions soap engagements can function as career stepping stones. Consequently, we focus on the characteristics of acting in serials and identify the implications for the future development of (young) actors and their prospects on the labor market. Extensive biographical data of 396 former soap opera actors from Germany enables a quantitative investigation of artists' careers over time, a research gap pointed out by Towse (2006).

The remainder of this paper is structured as follows. Sect. 2 describes characteristics of soap operas and illuminates the work of actors in the filming of these series. Based on cultural labor market economics, the supply of acting services is explained and career trajectories of soap actors are explored in Sect. 3. Along these lines, soap operas are conceived of as career stepping stones; this discussion also develops the hypotheses. Sect. 4 describes the data and the methodological approach. In Sect. 5, the empirical results are presented. The discussion of the implications follows in Sect. 6 . The paper concludes with a brief summary and an outline of its limitations in Sect. 7.

\section{Characteristics of Soap Operas and Their Production Processes}

Within the television (TV) segment, so-called soap operas or simply soaps were among the first serial formats developed that succeeded to dominate programming schedules throughout the twentieth century (Hagedorn 1995, p. 40). The name goes back to a Newsweek article from 1939, describing North American daily radio shows targeting a young to middle-aged, non-working female audience. Initially, soaps were sponsored by consumer goods companies that designed continuing drama as a frame for delivering advertising messages to the growing middle class. While production budgets for these shows were naturally low, economic considerations required producers of later daily TV soaps with 60-minute episodes to tightly manage

\footnotetext{
${ }^{1}$ For better readability only the word 'actor' is used throughout this paper. If not specified, it includes and refers to all genders in equal ways.
} 
costs by avoiding expensive star actors, limiting props and extras, relying on indoor studio filming and keeping editing to a minimum. ${ }^{2}$

Even with local differences regarding storylines, structures, narratives and audiovisual styles, the success of soap operas is a worldwide phenomenon. Especially noteworthy is the overwhelming local ${ }^{3}$ and international success of Latin American 'telenovelas', a related but distinct form of soap operas. The profound changes in the media industry over the last two decades, however, have also affected the global success story of soaps. The liberalization of many markets and in consequence the increasing supply of highly diversified and thus precisely targeted programming, making niche content available for virtually every interest, and the proliferation of Internet-based anytime distribution systems have led to a significant increase of competitive pressures. Discontinued soaps across TV stations and countries, declining ratings (Kissell 2014; Bowes 2011), reduced circulation numbers of soap opera fan magazines (e.g. Soap Opera Digest) and economic turmoil of Latin American media companies with a high dependence on telenovelas (Luhnow and Pérez 2018) all attest the adverse consequences.

Albeit fewer in number, programming schedules across the world still feature soaps and the remaining ones-partly updated, redesigned to be relevant for younger audiences, shifted to primetime slots and equipped with larger production budgets-continue to resonate with viewers (Luhnow and Pérez 2018; Kissell 2014; Bowes 2011). Moreover, the influence of soap operas goes beyond the metrics of the sub-genre itself, as successful new formats adopt a range of inherent characteristics of soaps (Geraghty 2010). First, content is increasingly serialized and distributed over longer periods with cliffhangers at the end of episodes (and seasons) luring viewers to return. Second, plots privilege personal life stories and the emotional states of the characters over the underlying events that give the series their basic premise. Finally, ongoing narratives are better aligned to the temporal realities and perceptions of audiences, making them more synchronous and hence more involving (e.g. 192 episodes over 8 seasons of the 'real time series' 24-Twenty Four).

Soap operas focus on telling fictional stories about interpersonal relationships, social issues and matters of various lifestyles, with the narratives being more interested in the underlying human feelings of love, hate, envy, disappointment or happiness. The emphasis of the series is on talk and less on action (Allen 1995, p. 20) or the exaggerated events that provoke such human reactions. Consequently, the storylines appear rather trivial but unfold significant meaning for loyal viewers who are familiar with the personal histories of the depicted characters and the relationships between them, allowing for subtle and nuanced interpretations (Allen 1995, p. 8).

\footnotetext{
${ }^{2}$ During the 1990s, the production costs for one minute of the German soap opera 'Good Times Bad Times' were estimated at 3000 USD (Cunningham and Jacka 1996). The corresponding costs for one minute of primetime TV-drama exceeded 25,000 USD at that time (Matelski 1999). In 2010, the costs for a broadcasted minute of the German daily soap 'Home Sweet Home' ('Dahoam is Dahoam') amounted to 3000 EUR (Stern 2011), indicating only a modest cost development in more than a decade. This is remarkable against the background of surging production costs for other content (Opitz and Hofmann 2014).

${ }^{3}$ In the 1990s, telenovelas, for example, accounted for half of the total output of Mexico's largest media company and in Brazil, a regular audience of up to 40 million viewers was reached (Allen 1995, p. 2).
} 
Another characteristic of soaps is that multiple, often intertwined and dynamic storylines run parallel within episodes and over extended periods (i.e. over weeks and months), without the resolution of one plot ever concluding a series (Riegel 1996). New storylines are introduced and developed before others end.

Due to the on-going filming schedules and the low-cost nature of the production process, the working conditions of soap actors are intense. ${ }^{4}$ The most significant difference to other TV productions is a pronounced time pressure. Actors are provided with a block of scripts for multiple episodes two to three weeks in advance-filming of up to 15 episodes consecutively is common practice-but scripts are changed multiple times before the filming takes place, forcing actors to stay flexible up to the moment of final recording. Rehearsals are highly restricted and some scenes may not be practiced at all, so the interpretation of the script and the actual performance are expected to be right at the first time, also to avoid editing as much as possible. Moreover, directors do not guide or coach actors in the creative process; directors of soaps rather focus on the integrity of the overall narrative and not on individual performances. This gives actors some degrees of freedom regarding the interpretation of the characters but may also overstrain some artists. In addition, filming takes place highly out of sequence, making it more difficult for actors to ensure continuity. For example, all on-location scenes (for up to 15 episodes) may be shot during some days, with all studio scenes being filmed during the following days.

Although filming schedules are published in advance, rosters for individual actors can be highly irregular and sporadic or temporarily more than full-time for those who portray characters with much airtime. Repeated 12-hour working days can be common, also due to the fact that some actors are paid on a per day basis (Kirsch 2001). Since in soaps, the camera focus is often on the characters, the actors are highly exposed in an environment with harsh lighting, no music and scenes being captured by three cameras (i.e. to reduce the need for re-filming scenes). In order to ensure that novices and even amateur actors can cope with the demanding working conditions, some production companies employ professional coaches who support the artists with additional trainings or help them prepare for upcoming scenes (Kirsch 2001).

While the casts are more or less stable-with the exception of discontinued and/or newly introduced characters every few months or years-the directors and other crewmembers like writers change frequently. Typically, the production process does not contemplate professional contact between actors and writers, clearly limiting the influence of the actor on her character development. ${ }^{5}$ The fact that the future evolution of characters and even parts of their own history are unknown and only unfold as the series continue (i.e. at the discretion of the producers and writers), embodying these personas can be a challenge for actors. Further personal or

\footnotetext{
4 The following descriptions are based on qualitative interviews with soap actors that are documented in Cantrell and Hogg (2017) as well as on various chapters from Cantrell and Hogg (2020) and Allen (1995).

5 However, informal contacts between actors and writers do happen and the latter tend to accommodate creative suggestions of their acting colleagues. In some soaps, more formal and periodic processes involving the script producers or other executives enable actors to learn about planned storyline directions and offer a means to raise concerns or make suggestions regarding character development. Nevertheless, the creative influence of actors remains clearly limited, as most soap operas are writer-dominated.
} 
even psychological dilemma may arise when the script requires actors to portray characters in contentious storylines that instigate public controversy or some form of other emotional public reaction. Finally, actors have little control over the length of their involvement, raising issues of job security. Many roles are initially cast for a limited side storyline but depending on the audience's resonance, contracts may be prolonged and/or the airtime of the characters significantly increased.

\section{The Labor Market for Actors: Career Implications of Starring in Soap Operas}

The analysis of artistic labor markets and artists as economic agents is based on the seminal works of Baumol and Bowen (1966). Various studies have explored the nature of artistic work and the implications for cultural labor markets (e.g. Throsby 2010; Towse 2006) because the dynamics differ from those of other professions. That is partly due to the difficulties surrounding personal talent and an inherent ideological dimension (Menger 2006); among a range of cultural professions, TV and film acting is at the heart of that discussion.

The prime characteristic of acting is that the financial rewards, all else being equal, are generally below those of comparable occupations (Throsby 2010; Alper and Wassall 2006; Throsby 1996). While superstar incomes are highly visible in the media, they are clearly restricted to the very few who make it to the top (Hofmann and Opitz 2019). In such winner-take-all markets (Frank and Cook 1991), the majority of actors needs to hold multiple jobs to compensate for otherwise insufficient income. While advancing their favored acting careers (Throsby and Hollister 2003), thus, many artists are dependent on less preferred part-time or even full-time jobs, both, in occupations in which acting skills may be useful (e.g. voice acting or teaching) and in areas unrelated to their core creative practice (Frey 2019, p. 33; Casacuberta and Gandelman 2012; Throsby and Zednik 2011). In general, cultural labor markets are characterized by excess supply (Menger 2006; Towse 2001b), giving organizations that hire artists a wide choice. Especially for actors, work in their preferred field is often unavailable, making other jobs a necessity to secure a decent standard of living. Menger (2006) interprets multiple jobholding as occupational risk management in cultural labor markets with contingent employment. Further characteristics of contingent work systems include temporary work, selfemployment and involuntary part-time work (Kalleberg 2000).

The financial rewards of actors are not only lower, they also vary to a larger degree (Throsby 2010). The discontinuity of filming activity leads to intermittent employment within projects and between different engagements (Benhamou 2011) and causes an inherently flexible work structure (Haunschild 2003). The realized income of actors is mainly generated via non-standard forms, such as project-based self-employment and temporary contracts (Menger 2006; Benhamou 2000). In hope (and hunt) for the next big leading role, also non-lucrative supporting roles are commonly accepted. Such labor market conditions are not suited for risk-averse individuals and those who enter the market must either have a certain risk appetite or 
overestimate their chances of success. Along these lines, artists have been compared with entrepreneurs (Hausmann 2010) and small businesses (Throsby 2010).

Due to the above-described demanding working conditions and the low aesthetic appreciation, roles in soap operas may be perceived as especially inferior vis-à-vis other engagements, but at least they give artists the paid opportunity to engage in their core creative and preferred activity of acting.

The longer an actor embodies a specific role in a soap opera, however, the more the actor's personality and the fictional character's persona amalgamate in the perception of the audience (Leppert 2018). Consequently, viewers rather recognize the more visible character versus the actor and constrain the latter to the specific serial context (Butler 1995, p. 159). This is because most actors are rather unknown for prior roles, the actors' names are typically not shown in the front credits and the daily routine of character-audience interaction in highly emotional narrative contexts triggers intensity and a high level of involvement (Hayward 2009, p. 144). This in turn limits the actor's future versatility and hence employability for different roles (Cantrell and Hogg 2017, p. 63; Benhamou 2011, 2000). When considering that cultural goods have an 'infinite diversity' (Caves 2000), actors are required to build a broad reputation by exceling in as many and as prestigious projects as possible. With increasing time spent in the cast of a soap, however, an actor becomes 'specialized' and will find it more difficult to diversify her repertoire (Leppert 2018). Knox (2020), for example, highlights the cases of British soap actors who migrate to the United States to circumvent being typecast - a strategy that not every artist is willing and able to pursue. Consequently, a biased audience perception over time and casting executives incorporating a lower role versatility in their decisions lead to the first hypothesis:

H1: The longer an actor remains in the cast of a serial, the lower the number of acting jobs in the post serial career phase. ${ }^{6}$

After exiting a soap, young actors (versus older ones) may find it easier to diversify their repertoire and alter their public image as one becomes older. For example, a more mature image may be easily supported by simple means of clothing, haircut or diction. A younger age may thus attenuate the above-mentioned perception bias of the audience.

In the case of older actors, on the other hand, the character's and the actor's personality may be linked more closely so that the typecast is firmly established in the perception of the audience. As image transitions are generally less credible with increasing age, older actors may be less suited for roles in other productions following a soap engagement. These considerations translate into the second hypothesis:

H2: The younger the actor at the time of leaving a serial, the higher the number of acting jobs in the post serial career phase.

Playing a character in the cast of a soap opera may be interpreted as on-the-job training, which is highly valuable for multiple reasons. First, studies have shown that practical experience has a positive effect on artists' income (Throsby 1996).

\footnotetext{
${ }^{6}$ In the empirical models, the post serial career phase is fixed to the same amount of time for all actors.
} 
This may be explained by drawing on 'household production theory' (Michael and Becker 1973) and applying it to the supply of artistic labor, as suggested by Caserta and Cuccia (2001). They show that engaging in artistic activity, while offering acting services towards the production of a sellable cultural good (here, episodes of the soap opera), increases the expertise and skills of the artist. That in turn lowers the costs for the production of the next output unit of the actor, so it can be understood as an educational experience that increases the human capital of the actor, without explicitly dedicating an investment towards the accumulation of human capital. Starring in a soap opera may thus enable an actor to earn a living and augment her skills via practical experience, with the latter being highly beneficial for obtaining future roles in other productions (Christopherson 2009).

Due to frequent filming and nearly instant feedback (i.e. episodes are aired about two to six weeks after filming), soaps are particular suited to gather practical experience and advance one's professional abilities. However, as with any learning experience and in particular in the case of the continuous but repetitive work in the cast of soap operas, the marginal rate of acquiring new competences diminishes rather quickly, hence flattening the learning curve over time.

One means to gain practical experiences and accumulate incremental skills on a continuing basis is to seek additional roles in other productions while being in the cast of a soap opera. These 'outside' jobs help artists to broaden their repertoire and avoid an overly specific typecast driven by the character embodied in the soap. Since the filming and production of TV content is characterized by significant discontinuity (Benhamou 2011), even actors whose characters are dominant in a current storyline and receive much airtime can engage in such career optimization behavior. ${ }^{7}$

While multiple jobholding may be a mere necessity to ensure an adequate standard of living in the short-term, it may also be useful to augment and diversify practical experience to manage one's long-term career. An actor's filmography, hence, reflects the extent of the completed on-the-job training. The longer the personal track record and the more distinguished projects listed there, the more likely it is that an artist obtains future roles because relevant competences in acting are documented (Zuckerman et al. 2003).

Finally, additional engagements, even supporting roles or jobs in smaller productions, enlarge the professional network to colleagues, directors, producers, casting managers and talent agencies. These network ties have been identified as an important success factor for an acting career (Wirtz, Mermann and Daiser 2016b; Blair 2009). Consequently, more profound experiences and a larger professional network should both be beneficial for obtaining future roles. These two effects support the following hypothesis:

H3: The more appearances an actor has in other productions while being in the cast of a serial, the higher the number of acting jobs in the post serial career phase.

The meaning and value of formal acting education offered by drama schools or colleges of performing arts, on the other hand, have also been discussed extensively

\footnotetext{
7 Exclusivity clauses in contracts, if legally allowed and enforced by a production company, may restrict an actor to accept other roles while being in the cast of a soap opera.
} 
in the literature on cultural labor economics. The traditional view treats the financial and other efforts of education as an investment in human capital, such as critical skills and expertise, which promise a return over an individual's professional career (Becker 1964). Because innate talent and creativity are already necessary conditions to pass the relatively strict entrance requirements, the 'real' contribution of schools and colleges has been challenged. Towse (2006) suggests that students learn the craft elements of their profession (e.g. presenting their work, internalizing techniques, etc.), receive the opportunity to build networks, gain access to specialist facilities (e.g. rehearsals on stage) and have a forum for displaying their talent. The latter is particularly important because career decisions rely on feedback that artists receive from audiences (MacDonald 1988). While most of these educational effects already depart from the traditional human capital view, empirical observations cast further doubt on the effectiveness of formal education for actors. First, surveys reveal that a considerable proportion of working artists did not attend any specialized school or college (Towse 2001a). Second, diplomas or other continued education certificates have been shown to have at best small, no or even negative effects on later income (Throsby 1994; Filer 1990; Wassall and Alper 1985), clearly contrasting Becker's (1964) conception of the returns of human capital investments. This may be the case because the multitude of artistic institutions produces a plethora of graduates with leaving certificates that are poorly suited to distinguish between different levels of artistic excellence (Towse 2006). The elaborate and time-consuming screening procedures of production companies and other hiring organizations before making final casting decisions further support this notion (Towse 1996). For obtaining a role, the innate characteristics of actors such as talent and motivation as well as experience (cf. explanations leading to hypothesis 3 above) seem to be factors that are more important than formal artistic education (Menger 2006).

Furthermore, today's formal acting education has been criticized for being widely based on the paradigms, techniques and special requirements of theater stage acting (Rawlins 2020; Cantrell and Hogg 2017, p. 38). While professional skills and techniques for memorizing scripts, immersing in the emotional state of characters and expressing authentic emotions are indeed conveyed, young actors feel insufficiently prepared for the job market and realize that critical abilities for a successful career in modern media are better acquired in the course of practicing (Jackson, Honey, Hillage and Stock 1994). The craft elements learned in school, however, may be useful for other arts-related work, which artists faced by insufficient creative job opportunities often pursue to ensure an adequate level of income. In an Australian sample, Throsby and Zednik (2011) found that actors spend 24\% of their time on activities such as teaching or administrative jobs in the cultural sector. Voice acting in animated formats or for dubbing foreign imported content are also popular jobs. These activities are clearly preferred over non-arts work because by their very nature, they are near to an artist's heart and allow generating returns from already acquired skills and existing talent (Throsby 1996). While theoretically the impact of formal education on the 'core career' of actors remains ambiguous, the effect on arts-related employment is captured in the fourth hypothesis: 
H4: Formal acting training prior to a serial engagement increases the number of employments in acting-related occupations in the post serial career phase.

The precarious working conditions of actors do not appear to mitigate the excess of labor supply that is observed in practice (Towse 2001b). The existence of nonpecuniary rewards may explain why so many individuals are motivated to pursue a professional acting career. On the one hand, individuals decide to become actors because acting is what they deeply want to do, leading to high levels of intrinsic motivation, especially among young artists (Frey 2019, p. 32). A general commitment to the profession causes a preference for acting, but economic constraints often mediate (i.e. reduce) the time and effort allocated to creative work (Throsby 2007). Nevertheless, the intrinsic motivation must be strong, as empirical evidence shows that artists "often forgo lucrative alternative employments in order to spend more time pursuing their creative work." (Throsby 2010).

On the other hand, screen or airtime resulting from a serial engagement offers actors a source of publicity, social recognition and celebrity status. A broad audience may get to know the actor not only via the depicted character on screen that typically only loyal fans follow. Through general media coverage in newspapers, magazines or the yellow press, a wider audience may learn about the actor and/or her character, leading to general awareness for and publicity surrounding the actor. Fame may be enjoyed as a psychic benefit (i.e. as an additional non-pecuniary reward) but the advancements in modern information and communication technology also enable actors to exploit publicity in a commercial way, for example via social media (Opitz and Hofmann 2008). While the direct monetary rewards of such activities may be a welcomed income opportunity for otherwise struggling artists, publicity may also foster core acting careers because well-known actors are valuable inputs for other productions. Popular artists, for example, may signal a film or serial's genre and draw attention to it, thereby facilitating the promotional activities (Hofmann 2021). Furthermore, viewers may generally prefer content starring prominent actors due to heightened gossip potential (Hofmann 2021). Thus, today's popularity and fame are important determinants of an actor's employment opportunities tomorrow. The last hypothesis summarizes these considerations:

H5: The higher the publicity of a TV series actor, the higher the number of acting jobs in the post serial career phase.

\section{Method and Data}

The data used is a unique collection of biographical information on all actors who had been starring in one of the five most successful German daily soap operas ${ }^{8}$ in

\footnotetext{
8 The following soap operas are included: 'Gute Zeiten Schlechte Zeiten' ['Good Times Bad Times'], 'Verbotene Liebe' ['Forbidden Love'], 'Marienhof' [name of a fictitious neighborhood in Cologne], 'Unter Uns' ['Among Us'] and 'Alles was zählt' ['All That Matters']. For all soaps, casts were identified starting with the first broadcasted episode. The sample begins on May 11th, 1992, the day 'Gute Zeiten Schlechte Zeiten' went on air.
} 
the 1990s and 2000s and left the casts before the cutoff date of February 6th, 2009. Accordingly, the sample consists of 419 former soap actors. The average number of exits per year for the 18 years under consideration is $22 .{ }^{9}$ Except for the first and last year, which are not full years, annual exit rates are similar, leading to a stable distribution of exits over time. ${ }^{10}$ In addition to gathering various biographical data like gender, date of birth, education and employments of the actors prior to entering the soap (if applicable), the individual filmographies, other practical experiences and person-specific media credits were researched for a ten-year period following the individual soap exits. The earliest documented exit in the sample is from the year 1992 and the latest post-soap career period for the last actor (i.e. who left one of the soaps just before the above-mentioned cutoff date) ended in 2019. Hence, the duration during which the careers were tracked is fixed to ten years for all actors but the periods vary depending on the individual exit dates. Various websites were used as data sources, including but not limited to the official homepages of the soap operas and their fan clubs, personal homepages of the actors as well as their talent agencies and the IMDb database. In some cases, actors or their agencies were contacted directly.

For the following analyses, four observations for actors younger than eight years of age were dropped because in these cases a deliberate acting career that is planned by the individual herself is very unlikely. One person deceased during his active time in the soap, which led to the exclusion of the corresponding data set. In order to use a consistent sample for all empirical models, 18 actors for whom certain pieces of information were unavailable were further dropped, reducing the final sample to 396 observations. ${ }^{11}$

In order to analyze whether or not a soap engagement can be a stepping stone for an actor, the number of acting jobs following the soap engagement are regressed on a number of possible influencing factors. Two dependent variables are used that differ in the time period in which the acting jobs were counted. TOTALACTING counts the roles in TV films or serials, including casting and reality shows, feature films and appearances in commercials during the ten consecutive years after the exit of an actor from a soap. Given this operationalization, the variable treats all employments of an actor equally and measures the mere length of an artist's filmography. Since roles in serial formats are only counted once regardless of the duration of employment, the variable does not necessarily reflect total screen appearances or cumulative screen time. For the purpose of this research, the number of different roles is used to measure the intensity with which an artist is hired and paid for jobs following the soap engagement that require some sort of acting competencies. So, TOTALACTING is one conception of an actor's occupational success that avoids a likely difficult assessment of job quality when the latter may be determined by a diverse mix of criteria from disciplines such as economics, finance, the

\footnotetext{
9 Calculation based on the final sample $(n=396)$, which is used for all subsequent analyses.

10 The annual exit rate for the 16 full years amounts to 24 on average.

11 Robustness checks for the final models shown in Sect. 5 indicate that including these observations when possible does not structurally alter the results.
} 
arts, psychology or even sociology. ${ }^{12}$ The same approach is applied for the variable LATEYRSACTING, however, only for years six through ten. Since formal acting education is not expected to impact core acting careers in a systematic way, H4 is tested in a model with the cumulative number of voice acting jobs as the dependent variable (VOICEACTING), also over the full ten-year period. Due to the nature of count data and overdispersion in the sample at hand, all models are estimated using negative binomial regression. Further, robust standard errors are reported for all coefficients.

The independent variable DURATION measures the time in years an actor appeared in a given soap. A squared term of the variable (DURATION2) is used to model non-linear effects. EXITAGE indicates an actor's age at the time she left the soap. If an actor took acting lessons or was enrolled in drama school, the binary variable ACTORTRAINING is set to unity, zero otherwise. The variable ROLESDURINGSOAP counts the number of side jobs an artist had while being in the cast of a soap. For collecting these pieces of information, the filmographies and resumes of the actors were consulted for the period in which she appeared in the soap. Hence, this variable measures the amount of additional on-the-job training and to which degree an actor has enlarged her professional network.

The following binary control variables are included in all models. MUSICTRAINING indicates if an actor received some form of training as a musician (e.g. vocal and/or instruments). While the skills acquired may be useful for matching specific role requirements, thereby increasing the versatility of an actor, the training may also sharpen generic competences that support the artistic performance (e.g. voice alteration, confidence of performing in front of audiences, etc.). The dummy variable PREACTING controls for an artist's acting experience prior to joining a serial. The variable is set to unity if the person's filmography indicates at least one engagement before being cast for the soap. Hence, the variable captures both, extant practical experience and potentially an existing network of professional contacts that may have been helpful for securing the role in the soap but also for future castings. The variable MALE specifies the gender of an artist; the binary regressor equals 1 for men and 0 for women. Further, all models include serial dummies identifying from which soap an actor departed; the omitted category is 'Good Times Bad Times' in all cases.

Two additional explanatory variables are included in the model with LATEYRSACTING as the dependent variable. Here, FIRSTYRSACTING is included as a regressor to control for the scale of an actor's career during the first five years after leaving the soap (i.e. her success in being cast for productions). It is reasonable to expect that actors with a more extensive track record and hence a broader repertoire are more likely to be hired for new roles (Wirtz, Mermann and Daiser 2016a). In addition, FIRSTYRSMEDIA operationalizes the visibility of an actor in the wider German media landscape and hence is a proxy for publicity and popularity among a broader audience beyond the fans of a soap. The variable captures a period of up

\footnotetext{
12 Incomplete or vaguely reported pieces of information regarding actors' jobs and roles also cause limitations for the construction of the dependent variables. This weakness is further elaborated on in the final section of this paper.
} 


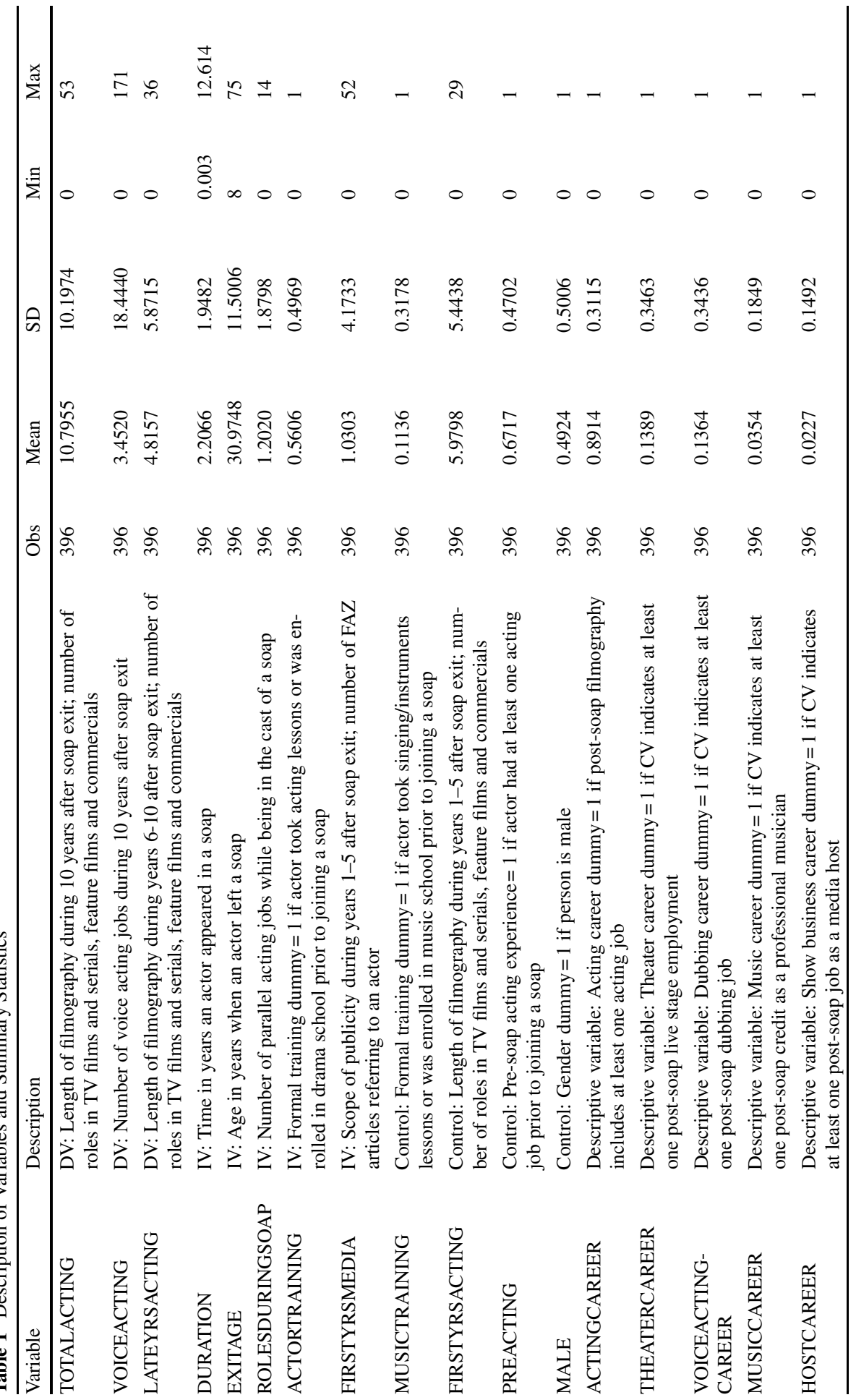


to five years immediately following the exit. To construct it, we searched for the full name of an actor in the online archive of 'Frankfurter Allgemeine Zeitung' (FAZ), a leading daily newspaper with a renowned feuilleton section and national distribution in Germany. The number of times an artist appeared in these searches was counted. This particular media outlet was selected due to technical aspects that relate to data availability: Since the sample stretches back to the early 1990 s, a database had to be consulted that covered consistently the entire period with sufficient entries. The intention was to measure an actor's overall media presence, particularly not focusing on the specialized titles targeting soap opera fans, because general popularity is considered beneficial for obtaining further acting jobs (Hofmann 2021). The comparably long period of five years, which may be longer than some actors' soap tenure, had to be selected to obtain enough observations with non-zero values. Table 1 defines all variables used and displays the respective summary statistics. ${ }^{13}$ The dummy variables in the last five lines indicate in which sector of the media industry an actor has found employment after the soap engagement. Besides continuing acting (ACTINGCAREER set to unity, zero otherwise) we observe if an artist has participated in at least one live stage production (THEATERCAREER), has completed a dubbing project (VOICEACTINGCAREER), has been active as a professional musician (MUSICCAREER) and/or has been employed as a media host (HOSTCAREER). These five variables are used for some complementary descriptive analyses below.

\section{Results}

Table 2 depicts the results of three specifications with TOTALACTING and one specification with VOICEACTING as the dependent variables. In the first column, the independent variable ROLESDURINGSOAP is not yet included. The significant coefficients of the variables capturing the length of the soap engagement suggest that the effect on the career is curvilinear (i.e. inverted u-shaped). Initially, playing a role in a soap increases the prospects for future acting jobs up to a maximum of 3.78 years. After that point, however, remaining in the cast of a soap has a detrimental effect on the artist's career. This development may be explained by on-the-job training effects that are valuable in the beginning but diminish over time and a reduced role versatility of the actor due to audiences overly associating the actor with the depicted soap character. The latter effect is detrimental to the future career and predominates the beneficial training effect beyond the optimum. Neither the age of the actor nor professional acting education appear to be driving factors. The nearly significant variable PREACTING ( $p$-value of 0.150 ) may suggest that experienced actors, who join a soap, might have better later career prospects than amateurs have.

In specification 2, the variable capturing acting side jobs (ROLESDURINGSOAP) is introduced. Its positive and highly significant coefficient suggests that the occupational activity level of actors whilst starring in a soap opera has a beneficial impact

13 A correlation matrix is not shown but available from the author upon request. Pairwise correlation coefficients of variables included in the models are low, indicating no issues of multicollinearity. 


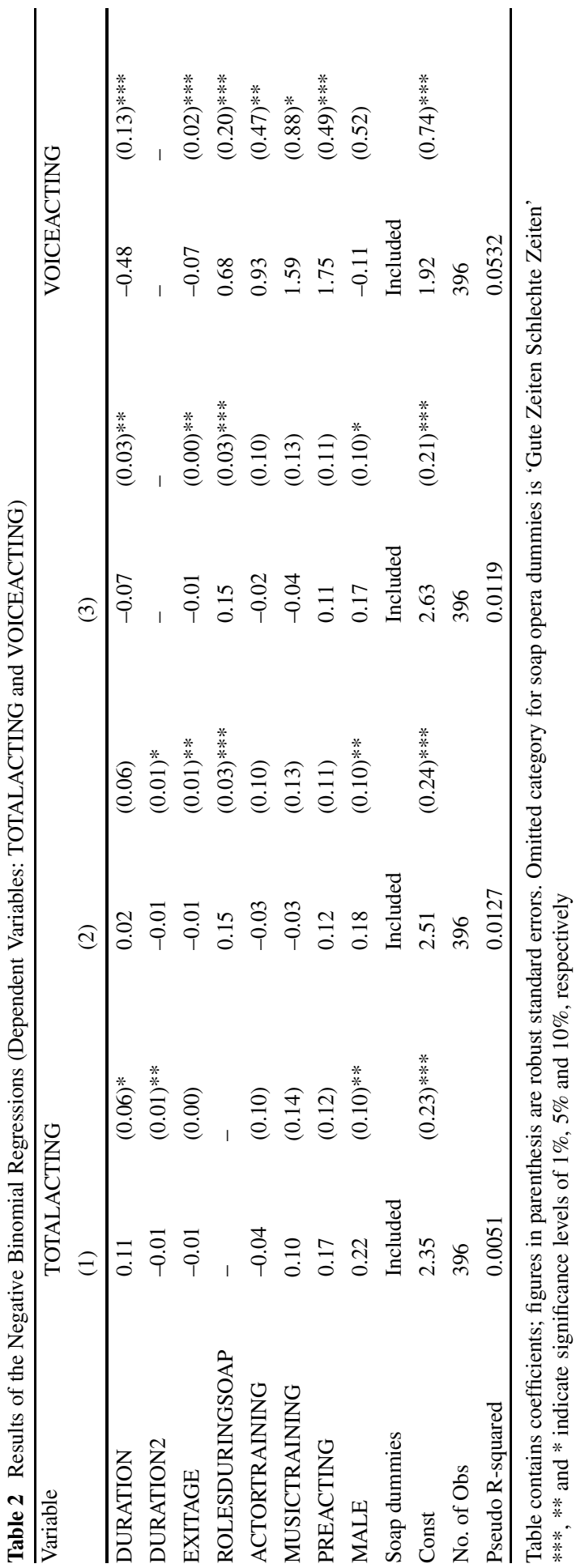


on future roles, an empirical finding that is in line with H3. Interestingly, the addition of this variable renders the curvilinear effect of DURATION insignificant but turns the negative coefficient of EXITAGE statistically significant. These changes merit further explanation. While the age of actors showed no significant impact in the first model, controlling for what the artists do parallel to acting in a soap indicates that younger artists - all else being equal, especially regarding appearances in other shows-have advantages in finding future roles. Although the inverted u-shaped relationship between the duration and subsequent acting success was theoretically comprehensible, a linear negative effect makes sense when accounting for the additional practical experiences gathered outside the soap. Hence, the optimal point in time to leave a soap as calculated above is arbitrary. The length of soap participation should rather be as short as possible but long enough to secure sufficient other acting jobs. The now clearly insignificant coefficient of PREACTING further suggests that previous experience may indeed help to get a role in a soap opera (as per Table 1 above, $67 \%$ of the actors in this study exhibit some form of previous experience) and other immediate engagements ${ }^{14}$ but that it is not relevant for the long-term career prospects. It appears as if in the acting profession the number and potentially the prominence of today's roles highly determine an artist's career tomorrow. 'Older' engagements, on the other hand, lose their influence rather quickly. In this sense, the entertainment industry seems to be fast moving and forgetful to achievements from the past. In other words, decision-making in castings may be prone to a recency bias.

Since a linear effect of DURATION fits better to the data, the squared term DURATION2 is dropped in specification 3. This final model is used to test hypotheses 1 to 3 . The negative and statistically significant coefficient of DURATION provides evidence in favor of H1. Likewise, the estimate for EXITAGE supports $\mathrm{H} 2$. Gathering additional practical experience via side jobs and thereby enlarging one's professional network is a strong predictor of future acting employment. The highly significant coefficient of the variable ROLESDURINGSOAP, thus, lends strong support to $\mathrm{H} 3$. The coefficients for the variable measuring actors' formal training are insignificant in all three specifications, a result that is in line with the theoretical explanations above. In the model that predicts the number of voice acting jobs following a soap engagement, however, ACTORTRAINING has a positive and statistically significant coefficient, providing clear evidence in favor of H4. Interestingly but also little surprising is the significant coefficient of MUSICTRAINING, a variable that controls for formal vocal training or some education as a musician. The acquired skills in such trainings should be helpful when seeking employment as a voice actor.

Table 3 includes the results for the career development in years six through ten after exiting a soap. This model is used to test the last hypothesis. The significant coefficient of FIRSTYRSMEDIA lends support to H5. In this model, some of the observed effects from above have changed. While the age of a former soap actor continues to be important for the long-term career (i.e. the younger the better), the

\footnotetext{
${ }^{14}$ In an unreported complementary negative binomial regression with ROLESDURINGSOAP as the dependent variable, a positive and highly significant coefficient of PREACTING further attests this effect.
} 
Table 3 Results of the Negative Binomial Regression (Dependent Variable: LATEYRSACTING)

\begin{tabular}{lll}
\hline Variable & LATEYRSACTING & \\
\hline DURATION & -0.02 & $(0.03)$ \\
EXITAGE & -0.02 & $(0.01)^{* * *}$ \\
ROLESDURINGSOAP & 0.03 & $(0.03)$ \\
ACTORTRAINING & 0.11 & $(0.11)$ \\
MUSICTRAINING & 0.11 & $(0.18)$ \\
FIRSTYRSMEDIA & 0.02 & $(0.01)^{*}$ \\
FIRSTYRSACTING & 0.14 & $(0.01)^{* * *}$ \\
PREACTING & 0.23 & $(0.12)^{*}$ \\
MALE & 0.18 & $(0.11)^{*}$ \\
Soap dummies & Included & \\
Const & 0.66 & $(0.24)^{* * *}$ \\
No. of Obs & 396 & \\
Pseudo R-squared & 0.0854 & \\
\hline
\end{tabular}

Table contains coefficients; figures in parenthesis are robust standard errors. Omitted category for soap opera dummies is 'Gute Zeiten Schlechte Zeiten'

$* * *, * *$ and $*$ indicate significance levels of $1 \%, 5 \%$ and $10 \%$, respectively

time spent in the cast of the soap becomes irrelevant when controlling for the number of roles played in the five years following the soap (FIRSTYRSACTING). Here, the hiring organizations' focus on an actor's recent accomplishments becomes evident again.

Finally, the positive and significant coefficients of MALE in all models with acting-related dependent variables indicate that men, all else being equal, play more roles than women do in their post-soap careers. Although the data used for this research does not allow investigating the underlying reasons, the observed effect corresponds to studies that analyse gender inequalities in the motion picture industry: "Women receive fewer roles and have less star presence than men" (Lincoln and Allen 2004), especially as they grow older.

\section{Discussion and Implications}

The empirical results provide some guidance for the management of careers in the entertainment industry and especially address under which conditions a serial engagement may function as a stepping stone.

When analyzing the different stages of actors' careers, here the pre-soap stage, the time in the soap, the ten years following the soap and the period covering years six through ten, a recurring theme is the importance of past practical acting experiences as a determinant of new engagements. As already pointed out above, casting directors appear to succumb to a recency bias and value especially fresh experiences. This is not surprising as the phenomenon has been known for long in the creative industries. In fact, it is well described for the film industry (Blair 2001). Consequently, an acting career does not only need to gain momentum via first roles initially but it is equally important to maintain that momentum over time. 
Although soap operas are typically not considered a good starting point for a serious acting career (Brennan 2004), the results of this study indicate that soaps can indeed be a stepping stone. It is remarkable that $89 \%$ of the actors included in the sample remained in acting for at least one additional role, with an average of 12.1 acting jobs over the following ten years (10.8 roles on average for the entire sample; cf. Table 1). Against the background of the high percentage of soap actors that can draw on some prior acting experience (i.e. 67\%) and the significance levels of the PREACTING and ROLESDURINGSOAP variables, one can conjecture that experienced actors may be better able to cope with the strenuous filming conditions of soap operas or with any production of filmed entertainment in general. The experiences gathered on one set might complement those from previous jobs and in combination, further augment the skills of an artist, in turn making the candidates better suited for future engagements. As an alternative explanation, professional contacts and an enlarged network to colleagues, directors, producers, casting managers and talent agencies can be responsible for the observed positive effect of acting experience. Knowing more of the right people, simply due to a longer filmography of completed projects, can be a big advantage to learn about current role openings and win casting competitions.

The insignificant effect of the variable capturing formal acting education (ACTORTRAINING) on the core career of screen acting supports the notion that classical human capital considerations do not fully hold in this profession. Practicing the art of acting in a soap but even more importantly in other diverse roles is superior for acquiring the skills and competences needed in practice and hence is a better predictor of future employments. The facts that $56 \%$ of the actors in this study had received formal training ${ }^{15}$ before being cast for a soap but that the vast majority (89\%) remains active in the profession, further attest soap operas some qualification function at least for amateur actors. While drama schools and colleges of performing arts obviously rather perform a sorting function for already talented individuals (Towse 2006), they also convey critical skills that are helpful for finding jobs in arts-related occupations. The significant positive effect on voice acting employment attests this. Given the scarcity and poor pay of acting jobs on the market, arts-related income is not only important for actors to make a living, it also enables them to avoid less preferred and worse paid non-arts jobs (Throsby 1996). Acquiring the right qualifications for arts-related jobs is thus an advisable occupational risk management approach (Menger 2006) that young actors should remember when embarking on a creative career. When considering that many graduates from public as well as private drama schools effectively enter the job market for television acting, artistic schools and colleges may want to revise the curricula of existing study programs to focus more on competences that enable graduates to cope with and excel in demanding industrial filming conditions. While on-stage live acting should not disappear from the curricula, integrating more training for mass media productions could be a better fit to the 'real' working conditions of many young actors.

15 The dimension of this figure is in line with results from surveys, for example as reported in Towse (2001a). 
Concerning the long-term career management of actors, the positive effect of popularity and media presence on artists' hiring opportunities should not be underestimated and left to chance. The more visible an actor during her early career, the larger the audience that at least knows her name or recognizes her face. Such general publicity is helpful for winning roles in other productions. To explore in detail how soap opera engagements can be a suitable platform to increase media presence is beyond the scope of this paper. Theoretically, a smart and well-designed media strategy may be helpful in creating and fostering a celebrity brand. In a complementary model, we regressed the total amount of media mentions for the full ten-year period following the soap engagement on a number of covariates from the analyses above. The strongest and by far most significant determinant is the number of acting jobs besides starring in a soap. Interestingly, the duration of the soap engagement itself has a negative effect on the visibility in the media. These two results indicate that job diversity is the preferred approach to building fame and that the soap engagement should again be rather short in order not to constrain valuable media presence.

Finally, we investigate if soap engagements may also function as a door opener for venturing into other domains of the entertainment industry. We refer to such transitions as artistic career migrations. Of the 396 former soap actors in our sample, for example, $14 \%$ pursued a theater career, $4 \%$ published songs as solo musicians or members of a band and $2 \%$ moderated TV or radio shows (compare Table 1 above). Admittedly, all of these migrations are quite rare and most artists assume side employments as theater and voice actors to compensate for the rather low and unsteady incomes of the average TV actor but some exceptional migrations can be observed. Prominent examples from the current study include the German musicians Jeannette Biedermann, Yvonne Catterfeld, Olli P. and Marcel 'Mars' Saibert. The latter embodied a musician in the soap 'Unter Uns', produced an album and performed two of his songs at a street concert as part of the soap's storyline. Throughout the show the songs were played as background music, the album was featured in various scenes and the producer used the broadcaster's website to give fans background information on the filming of that particular episode. The 'real' album was released one day after the concert in the soap and was heavily promoted in the environment of the show, for example via advertising and editorial coverage in other formats of the broadcaster. The first single release, 'Reason', entered the German billboard charts at rank 15 and remained in the Top 100 for nine consecutive weeks. This example illustrates that career migrations from serials can even be planned and arranged deliberately. In this regard, Centeno and Wang (2017) stress the importance of the involvement of so-called instrumental stakeholders who have a business interest in the artist, such as producers, TV networks and talent agencies, for the creation of celebrities. In times of exchangeable and readily imitable show concepts and content, media companies may find the creation of serial stars and their commercialization in other domains of the entertainment industry effective for binding audiences and diversifying their services (Chan-Olmsted and Chang 2003) at comparably low cost (Franck and Nüesch 2007). 


\section{Conclusion and Outlook}

The paper set out to shed light on the career paths of actors and addressed the question if serial engagements, in particular roles in soap operas, may function as a stepping stone for a subsequent acting career. By doing so, it adds to the scarce literature on actors and the economics of their profession. In contrast to the majority of existing research on cultural labor markets, that typically uses census or survey data, the study at hand is among the first to adopt a quantitative approach using secondary data, which traces the career developments of artists over an extended period.

The empirical results indicate that soaps may indeed function as a stepping stone for a serious acting career, especially for younger actors. Soap engagements, however, should be rather short but still long enough so that artists can play numerous roles in other shows or films while being in the cast of a soap. That broadens their repertoire and avoids that audiences overly associate an actor with the role played in the soap. While formal acting education is neither a prerequisite for being cast for a soap nor influences later career success, it is conducive for acting-related side jobs (e.g. voice acting), which are important sources of income for actors. Without a dedicated media strategy and additional roles in productions outside the soap, being in the cast of such a serial does not automatically boost media publicity. However, being recognized by a broad audience and in that sense being famous fosters a later acting career. Given these results, active soap stars are advised to build a celebrity brand that focuses on the 'real' actor behind the soap character because it is the former that is versatile and can be hired for other productions. In conclusion, the actual work in the cast of a soap is rather 'uncomfortable' but could be understood as an intermediary job that makes sense in the long run as it increases the chances of obtaining more and potentially better acting jobs down the road.

Given the current renaissance of serial watching (Orosz, Vallerand, Böthe, TóthKirály and Paskuj 2016) the results are highly relevant. Although the analysis is constrained to the particular sub-genre of soap operas, the insights should be transferable to other settings of serial content production, which remain a major source of income for TV actors and an especially lucrative one for big screen actors (Opitz and Hofmann 2016). While the particularities of the soap genre may be 'extreme', modern series feature similar characteristics, which increases the transferability of the results at hand. In an even broader context, other labor markets show interesting parallels to some dynamics of the here described labor market for actors. For example, managerial careers in today's business world heavily depend on previous practical experience, age and rather short-term affiliations with various companies versus lifelong tenure at one employer (Gallo 2015). Furthermore, many top executives have been trained originally in other fields than business (e.g. natural sciences, engineering or computer science).

The following limitations remain. First and most critical, the data prevents a more fine-grained distinction between acting jobs of different 'quality', both during and following the soap. We merely count roles, meaning that, for example, a one-time supporting role is treated equally to a recurring leading role in a successful TV series. This is inasmuch problematic, as career success is not only determined by the sheer 
number of roles but also by the artistic and/or economic merit of them. Alternative measures, particularly financial indicators such as income would be informative but are impossible to obtain for a large sample of actors that do not belong to the group of superstars. Moreover, obtaining such pieces of information might be easier for Hollywood stars but proves extremely difficult for smaller and less transparent media markets such as Germany. Turning to more accurate criteria for differentiating between acting jobs, for example by distinguishing between leading and supporting roles, is curtailed by pronounced fuzziness in the self-reported curricula vitae and filmographies of actors. Furthermore, leading parts in different projects may significantly differ in their economic and artistic value due to underlying differences in the projects. This imprecision is exacerbated when observing supporting roles for which a wide range of gradations exist. Hence, the validity of such variables would remain highly questionable. Related to this limitation is the fact that we are primarily concerned with the main creative work of acting and only include one variable for other arts-related work (i.e. voice acting). While non-arts work was not of interest here, it certainly plays an important role in the total income function of actors (Throsby and Zednik 2011; Throsby 1996). Second, we are not able to further break down the positive effect of previous experience into its potential 'on-the-jobtraining' and 'networking' components. The underlying mechanisms remain somewhat disguised, as both explanations are equally comprehensible. Third, we do not distinguish between the 'valence' of different soap roles. For example, playing the unpopular villain versus everybody's darling may have implications on the future career path of the embodying actor. Finally, the variable measuring media visibility is a rather crude proxy.

Despite these areas of improvement, the paper complements the literature that strives for increasing our understanding of the particularities of cultural labor markets and further illuminates the sometimes-opaque career paths of non-superstar actors. We hope that future research on the acting profession addresses the above-mentioned limitations and investigates the myriad of interesting aspects that remain unexplored. Against the background of the dynamic developments that currently transform the global television industry (Mooney, Burdon and Kang 2018), putting actors more in the spotlight of cultural, economic and social studies continues to be a fruitful research agenda.

Acknowledgements The author would like to thank two anonymous referees and the editors of the journal for insightful comments and important suggestions that further improved the quality of the paper. Moreover, he is indebted to Christian Opitz for inspiring discussions on the topic and Mona Wimmer for valuable research assistance. Finally, he acknowledges the conversations with Andreas Faatz, which have advanced the methodological approach.

Funding Research funded with resources from Osnabrück University of Applied Sciences.

Funding Open Access funding enabled and organized by Projekt DEAL.

Open Access This article is licensed under a Creative Commons Attribution 4.0 International License, which permits use, sharing, adaptation, distribution and reproduction in any medium or format, as long as you give appropriate credit to the original author(s) and the source, provide a link to the Creative Commons licence, and indicate if changes were made. The images or other third party material in this article are included in the article's Creative Commons licence, unless indicated otherwise in a credit line to the material. If material is not included in the article's Creative Commons licence and your intended use is not 
permitted by statutory regulation or exceeds the permitted use, you will need to obtain permission directly from the copyright holder. To view a copy of this licence, visit http://creativecommons.org/licenses/by/4. $0 \%$

Conflict of interest K. H. Hofmann declares that he has no competing interests.

\section{References}

Allen, Robert C. 1995. To be continued... soap operas around the world. London: Routledge.

Alper, Neil O., and Gregory H. Wassall. 2006. Artists' careers and their labor markets. In Handbook of the economics of art and culture, ed. Victor A. Ginsburgh, David Throsby, 813-864. Amsterdam: NorthHolland.

Anitha, K. 2014. Socio, economic and cultural impact of soap operas on home makers (A study in Andhra Pradesh). Journal of Mass Communication \& Journalism 4(4):1-6.

Baumol, William J., and William G. Bowen. 1966. Performing arts: the economic dilemma. New York: Twentieth Century Fund.

Becker, Gary. 1964. Human capital. New York: Columbia University Press.

Benhamou, Françoise. 2000. The opposition of two models of labour market adjustment. The case of the audiovisual and performing arts in France and in the United Kingdom. Journal of Cultural Economics 24:301-319.

Benhamou, Françoise. 2011. Artists' labour markets. In A handbook of cultural economics, ed. Ruth Towse, 69-75. Cheltenham: Edward Elgar.

Blair, Helen. 2001. 'You're only as good as your last job': the labour process and labour market in the British film industry. Work, Employment \& Society 15(1):149-169.

Blair, Helen. 2009. Active networking: action, social structure and the process of networking. In Creative labour - working in the creative industries, ed. Alan McKinlay, Chris Smith, 116-134. London: Red Globe Press.

Bowes, Peter. 2011. Do US daytime soap operas have a future? BBC News April 20, retrieved from: https:// www.bbc.com/news/entertainment-arts-13140622. Last access: October 19, 2021.

Brasch, Walter. 2006. Sex and the single beer can: Probing the media and American culture. Spokane: Marquette Books.

Brennan, Eddie. 2004. Soap opera, commercialisation and the proletariasation of cultural production. Irish Journal of Sociology 13:66-83.

Butler, Jeremy G. 1995. I'm not a doctor, but I play one on TV - Characters, actors and acting in television soap opera. In To be continued... Soap Operas Around the World, ed. Robert C. Allen, 145-163. London: Routledge.

Cantrell, Tom, and Christopher Hogg. 2017. Acting in British television. London: Red Globe Press.

Cantrell, Tom, and Christopher Hogg. 2020. Exploring Television Acting. London: Methuen Drama.

Casacuberta, Carlos, and Nestor Gandelman. 2012. Multiple job holding: the artist's labour supply approach. Applied Economics 44:323-337.

Caserta, Maurizio, and Tiziana Cuccia. 2001. The supply of arts labour: towards a dynamic approach. Journal of Cultural Economics 25:185-201.

Caves, Richard E. 2000. Creative industries. Contracts between art and commerce. Cambridge: Harvard University Press.

Centeno, Dave, and Jeff Wang Jianfeng. 2017. Celebrities as human brands: an inquiry on stakeholderactor co-creation of brand identities. Journal of Business Research 74:133-138.

Chan-Olmsted, Sylvia M., and Byeng-Hee Chang. 2003. Diversification strategy of global media conglomerates: examining its patterns and determinants. Journal of Media Economics 16:213-233.

Christopherson, S. 2009. Working in the creative economy: risk, adaptation, and the persistence of exclusionary networks. In Creative labour - working in the creative industries, ed. Alan McKinlay, Chris Smith, 72-90. London: Red Globe Press.

Cunningham, Stuart, and Elizabeth Jacka. 1996. Australian television and international mediascapes. Cambridge: Cambridge University Press.

Dias, José António, José G. Dias, and Carmen Lages. 2017. Can negative characters in soap operas be positive for product placement? Journal of Business Research 71:125-132.

Dunleavy, Trisha. 2009. Television drama: form, agency, innovation. Basingstoke: Palgrave.

Filer, Randall K. 1990. The arts and academe: the effect of education on earnings of artists. Journal of Cultural Economics 14(1):15-38. 
Franck, Egon, and Stephan Nüesch. 2007. Avoiding ,star wars' - celebrity creation as media strategy. Kyklos 60:211-230.

Frank, Robert H., and Phillip J. Cook. 1991. Winner-take-all markets. Papers in political economy 18. London: Political Economy Research Group.

Frey, Bruno S. 2019. Economics of art and culture. Cham: Springer.

Gallo, Amy. 2015. Setting the record straight on switching jobs. Harvard Business Review 93(10):34-36.

Geraghty, Christine. 2010. Exhausted and exhausting: television studies and British soap opera. Critical Studies in Television 5(1):82-96.

Götz, Maya. 2000. Die Bedeutung von Daily Soaps im Alltag von 10- bis 15-Jährigen. TelevIZIon 13:52-64.

Greenberg, Bradley S., and Mark G. Woods. 1999. The soaps: their sex, gratifications, and outcomes. Journal of Sex Research 36(3):250-257.

Hagedorn, Roger. 1995. Doubtless to be continued - a brief history of serial narrative. In To be continued... soap operas around the world, ed. Robert C. Allen, 27-48. London: Routledge.

Harrington, C. Lee, and Denise Brothers. 2010. A life course built for two: acting aging, and soap operas. Journal of Aging Studies 24:20-29.

Haunschild, Axel. 2003. Managing employment relationships in flexible labour markets: the case of German repertory theatres. Human Relations 56(8):899-929.

Hausmann, Andrea. 2010. German artists between bohemian idealism and entrepreneurial dynamics: reflections on cultural entrepreneurship and the need for start-up management. International Journal of Arts Management 12(2):17-29.

Hayward, Jennifer. 2009. Consuming pleasures - active audiences and serial fictions from Dickens to soap opera. Lexington: The University Press of Kentucky.

Hofmann, Kay H. 2021. The contribution of actors in film production and distribution: exploring the antecedents of the drawing power of stars. Celebrity Studies 12(4):529-548.

Hofmann, Kay H., and Christian Opitz. 2019. Talent and publicity as determinants of superstar incomes: empirical evidence from the US motion picture industry. Applied Economics 51(13):1383-1395.

Hogg, Christopher, and Charlotte Lucy Smith. 2020. Well-being and the television actor: challenges and coping strategies. In Exploring Television Acting, ed. Tom Cantrell, Christopher Hogg, 171-186. London: Methuen Drama.

Jackson, Charles, Sheila Honey, Jim Hillage, and John Stock. 1994. Careers and training in dance and drama. Report No. 268. Brighton: Institute of Manpower Studies.

Jones, Candace, and Robert J. DeFillippi. 1996. Back to the future in film: combining industry and self knowledge to meet the career challenges of the 21st century. Academy of Management Executive 10(4):89-103.

Kalleberg, Arne L. 2000. Nonstandard employment relations: part-time, temporary and contract work. Annual Review of Sociology 26:341-365.

Kirsch, Gunther. 2001. Produktionsbedingungen von Daily Soaps: Ein Werkstattbericht. montage/av 10(1):45-54.

Kissell, Rick. 2014. Daytime soaps enjoy a new surge in popularity. Variety, retrieved from: https:// variety.com/2014/tv/awards/daytime-soaps-enjoy-a-new-surge-in-popularity-1201153292/. Last access: October 19, 2021.

Knox, Simone. 2020. Exploring the casting of British and Irish actors in contemporary US television and film. In Exploring television acting, ed. Tom Cantrell, Christopher Hogg, 154-170. London: Methuen Drama.

Leppert, Alice. 2018. Friends forever: sitcom celebrity and its afterlives. Television \& New Media 19(8):741-757.

Liebes, Tamar, and Sonia Livingstone. 1998. European soap operas - the diversification of a genre. European Journal of Communication 13:147-180.

Lincoln, Anne E., and Michael Patrick Allen. 2004. Double jeopardy in hollywood: age and gender in the careers of film actors, 1926-1999. Sociological Forum 19(4):611-631.

Luhnow, David and Santiago Pérez. 2018. Netflix Breaks Up Audience Romance With Telenovela. Wall Street Journal April 23, retrieved from: https://www.wsj.com/articles/viewers-spurn-the-telenovelafor-a-new-love-netflix-1524501901. Last access: October 19, 2021.

MacDonald, Glenn M. 1988. The economics of rising stars. American Economic Review 78(1):155-166.

Matelski, Marilyn J. 1999. Soap operas worldwide: cultural and serial realities. Jefferson: McFarland.

McKenna, Mark. 2019. Sylvester Stallone and the economics of the ageing film actor. Celebrity Studies 10(4):489-503. 
Menger, Pierre-Michel. 2006. Artistic labour markets: contingent work, excess supply, and occupational risk management. In Handbook of the economics of art and culture, ed. Victor A. Ginsburgh, David Throsby, 765-811. Amsterdam: North-Holland.

Michael, Robert T., and Gary S. Becker. 1973. On the new theory of consumer behavior. Swedish Journal of Economics 75:378-396.

Middleton, Jerry C., and Jason A. Middleton. 2017. Review of literature on the career transitions of performing artists pursuing career development. International Journal for Educational and Vocational Guidance 17:211-232.

Mooney, Grant, Stephen Burdon, and Kyeong Kang. 2018. That's entertainment: crafting a creative ecology within public television. International Journal on Media Management 20(4):263-276.

Moore, Paul. 2004. Longing to belong: trained actors' attempts to enter the profession. $\mathrm{PhD}$ thesis. Sydney: University of Sydney.

O'Donnell, Hugh. 1999. Good times, bad times - soap operas and society in western europe. London: Leicester University Press.

Opitz, Christian, and Kay H. Hofmann. 2008. Integrierte Geschäftsmodelle zur Bewirtschaftung personengebundener Aufmerksamkeit - Das Beispiel der Daily Soap. MedienWirtschaft - Zeitschrift für Medienmanagement und Kommunikationsökonomie 5(4):16-25.

Opitz, Christian, and Kay H. Hofmann. 2014. Adverse selection and moral hazard in equity partnerships: evidence from hollywood's slate financing agreements. Journal of Economics \& Management Strategy 23(4):811-838.

Opitz, Christian, and Kay H. Hofmann. 2016. The more you know ... the more you enjoy? Applying 'consumption capital theory' to motion picture franchises. Journal of Media Economics 29(4):181-195.

Orosz, Gábor, Robert J. Vallerand, Beáta Böthe, István Tóth-Király, and Benedek Paskuj. 2016. On the correlates of passion for screen-based behaviors: The case of impulsivity and the problematic and non-problematic Facebook use and TV series watching. Personality and Individual Differences 101:167-176.

Patten, Robert L. 1975. Pickwick papers and the development of serial fiction. Rice University Studies 61(1):51-74.

Perez Taunay, Julia, Luiz Fernando Cardoso Santos Durao, Rodrigo Monteiro de Aquino, and Davi Noboru Nakano. 2020. Television stars and audience: an empirical analysis. Working Paper University of Sao Paulo.

Rawlins, Trevor. 2020. Exploring actor training for television. In Exploring television acting, ed. Tom Cantrell, Christopher Hogg, 127-139. London: Methuen Drama.

Reijnders, Stijn, Gerard Rooijakkers, and Liesbet van Zoonen. 2006. Global entertainment and local celebration: appropriations of the idols TV programme in Dutch festivity culture. European Journal of Cultural Studies 9:131-148.

Reynolds, Peter. 1998. Actors and Television. In Boxed Sets: Television Representations of Theatre, ed. Jeremy Rigman, 159-172. Luton: Luton: University Press.

Riegel, Henriette. 1996. Soap operas and gossip. Journal of Popular Culture 29(4):201-211.

Rubin, Alan M., and Elizabeth M. Perse. 1987. Audience activity and soap opera involvement: a uses and effects investigation. Human Communication Research 14:246-268.

Russell, Cristel, and Barbara Stern. 2006. Consumption in soap operas from Brazil, New Zealand, and the U.S.: production, products, and process. Advances in Consumer Research 33:134-137.

Scardaville, Melissa C. 2009. High art, no art: The economic and aesthetic legitimacy of U.S. soap operas. Poetics 37(4):366-382.

Stern, Henry. 2011. Seifenoper im Visier der Kostenkontrolleure. Main Post May 05, retrieved from: https://www.mainpost.de/ueberregional/bayern/seifenoper-im-visier-der-kostenkontrolleure-art6139196. Last access: October 19, 2021.

Tamborini, Ron, René Weber, Allison Eden, Nicholas David Bowman, and Matthew Grizzard. 2010. Repeated exposure to daytime soap opera and shifts in moral judgment toward social convention. Journal of Broadcasting \& Electronic Media 54(4):621-640.

Throsby, David. 1994. A work preference model of artists' behaviour. In Cultural economics and cultural policies, ed. Alan Peacock, Ilde Rizzo, 69-80. Dordrecht: Kluwer.

Throsby, David. 1996. Economic circumstances of the performing artist: Baumol and Bowen thirty years on. Journal of Cultural Economics 20:225-240.

Throsby, David. 2006. An artistic production function: theory and an application to Australian visual artists. Journal of Cultural Economics 30:1-14.

Throsby, David. 2007. Preferred work patterns of creative artists. Journal of Economics and Finance 31(3):395-402. 
Throsby, David. 2010. Economic analysis of artists' behaviour: some current issues. Revue d'Économie Politique 120(1):47-56.

Throsby, David, and Virginia Hollister. 2003. Don't give up your day job: an economic study of professional artists in Australia. Sydney: Australia Council.

Throsby, David, and Anita Zednik. 2011. Multiple job-holding and artistic careers: some empirical evidence. Cultural Trends 20(1):9-24.

Towse, Ruth. 1996. Economics of artists' training. In Economics of the arts, ed. Victor A. Ginsburgh, Pierre-Michel Menger, 303-329. Amsterdam: North-Holland.

Towse, Ruth. 2001a. Creativity incentive and reward. Cheltenham: Edward Elgar.

Towse, Ruth. 2001b. Partly for the money: rewards and incentives to artists. Kyklos 54:473-490.

Towse, Ruth. 2006. Human capital and artists' labour markets. In Handbook of the economics of art and culture, ed. Victor A. Ginsburgh, David Throsby, 865-894. Amsterdam: North-Holland.

Vicentini, Francesca, and Paolo Boccardelli. 2016. Career diversity and project performance in the Italian television industry. Journal of Business Research 69(7):2380-2387.

Wassall, Gregory H., and Neil O. Alper. 1985. Occupational characteristics of artists: a statistical analysis. Journal of Cultural Economics 9(1):13-34.

Wirtz, Bernd W., Marina Mermann, and Peter Daiser. 2016a. Success factors of motion picture actors - an empirical analysis. Creative Industries Journal 9(2):162-180.

Wirtz, Bernd W., Marina Mermann, and Peter Daiser. 2016b. Competencies and success of motion picture actors: a resource-based and competence-based empirical analysis. Journal of Media Practice 17(1):98-116.

Zuckerman, Ezra W., Tai-Young Kim, Kalinda Ukanwa, and James von Rittmann. 2003. Robust identities or non-entities? Typecasting in the feature-film labor market. American Journal of Sociology 108(5):1018-1074. 